\title{
Providing High Quality Standard of Training in the Tertiary Education Sector in Botswana: Evaluation of Resources in Enhancing Effectiveness
}

\author{
Sangodoyin Oluranti Olukemi ${ }^{1}$ \\ ${ }^{1}$ Gaborone Institute of Professional Studies, Botswana \\ Correspondence: Sangodoyin Oluranti Olukemi, Gaborone Institute of Professional Studies, Botswana. Tel: \\ 267-7-599-0945.
}

Received: August 1, 2017

Accepted: August 16, $2017 \quad$ Online Published: November 13, 2017

doi:10.5430/ijba.v8n7p73

URL: https://doi.org/10.5430/ijba.v8n7p73

\begin{abstract}
The research goal of study is to accentuate on high quality standard of training and provision of adequate resources and its effects on the overall development of tertiary education sector in Botswana. Special attention is paid to Botswana Qualification Authority (BQA) and it's emphasizes on the issue of compliance in the standards set by its regulatory authorities. This paper discusses opportunities for enhancing the efficiency of education by providing quality training and using resources more strategically to increase its impact on national and global education outcomes. Since Education Training Providers have advocacy for more students which has been targeted towards Directorate of Tertiary Education Council (DTEF), hence, attention to deliver effectiveness must be largely emphasized.

In programme development and procedures, delivery styles used on the programme must be appropriate to the needs of the learners. Adequate resources are necessary for successful achievement by learners of the programme objectives and maintain on the programme, and there should be plentiful evidence to indicate that the programme aspect meets expectations. Various resources for successful participation by learners are allocated to maintain programmes.

It has been deliberated that assessment must be available to all learners who have the potential to achieve the standards required for a particular qualification. Care must be taken that any proposed assessment methods are of quality for learners and demonstrate that they have achieved the international standard. Measures must be taken to ensure that all learners have adequate access to facilities and resources. The resources available to programmes must be in accordance with programme objectives and budget allocation. Finally, to ensure the introduction of relevant programmes in a socio-economic context; analysis of enquiries and administration of needs analyses must be conducted.
\end{abstract}

Keywords: tertiary institutions, Botswana Qualification Authority, training and development, quality management

\section{Introduction}

Botswana country maintained high rankings in Africa on most developed indices: the country ranked $3^{\text {rd }}$ in sub-Sahara Africa on the UNDP Human Development Index in 2015, and $3^{\text {rd }}$ in the Mo Ibrahim Index of Africa Governance in 2014 (Vision 2036). Education is important as it provide with the intellectual growth in which there is manpower development in the country. However, in order to achieve the much growth in the knowledge of the people in Botswana, there is need for providing enough resources to the entire education sector (Organisation for Economic Cooperation and Development, 2012). It is also essential to make the right policies that will make people to participate in the growth of the economy of the country. The defined goals and objectives of the quality of education for Botswana need to be well elaborated (Douglas and Douglas, 2006). In order to make the resources to be utilised efficiently there is need to create quality assurance both internal and external in the education sectors for example the Ministry of Education in Botswana.

Hence, there is a need for Botswana society to transform in response to the rapid and constant changes in education. Organizational effectiveness is a determinant of successful education institutions to achieve common goals particularly in this current age of dramatic change and high competition (Eddy, 1981). As in other organizations, measurement of effectiveness in public organizations can be carried out using the models despite with ambiguous, 
diverse, and sometimes contradictory goals in the latter (Organisation for Economic Cooperation and Development, 2008). Organizational effectiveness focuses on successful performances to achieve organizational goals and objectives. Harmon and Mayer (1986) provided consistent notion that effectiveness is the extent of achievement or success in implementing what is decided while evaluation is an activity of particular importance in the planning cycle and quality administration. It begins with planning, implementing, directing, monitoring, and evaluating project outcomes, leading to systematic and constant improvement and development of plans and projects (OECD, 2012). Standardized evaluation provides credibility and equity to all sectors. Effective evaluation requires transparency and accountability (Eddy, 1981).

\subsection{Statement of the Problem}

(a) Decline and low quality education standards provided in Botswana tertiary institutions

(b) Proliferation of private tertiary institution due to rapid increase in the number of eligible students graduating from secondary school.

(c) Poor service delivery resulting in denial of citizen's full enjoyment of many services offered

(d) Increased dependency ratio on government as beneficiaries are not able to graduate from the social assistance rendered by the government programmes

\subsection{Objectives of the Study}

(a)To investigate if tertiary institutions provide quality teaching and learning standards for effective educational training and skills development.

(b)To investigate if non-performance resulted in low quality of expertise provided and high unemployment rate was partially due to the fact that the supply of skills from the education sector does not match the needs of the job market.

\subsection{Research Question}

(a) Does the tertiary institution provide quality teaching and learning standards for effective educational training and skills development?

(b) Does non-performance resulted in low quality of expertise provided and high unemployment rate partly due to the fact that the supply of skills from the education sector does not match the needs of the job market?

\section{Review of Literature}

Research conducted by Organisation for Economic Cooperation and Development (OECD ,2008), revealed that internal assurance provides the system and mechanism to control, audit, and assess the implementation of educational facilities in line with the policies, goals. There should be extent of quality conforming to the standards defined by educational institutions and/or their parent organizations by establishing a quality assurance system within the institution (OECD, 2012). Its purpose is to provide people concerned with an insight on the connection of activities and intended outcomes, and what activities and goals are attained by the use of inputs and resources. Sirichai (2009) suggested that the logic model presents the causal relationship between input and process that leads to output and results which are combined as expected achievement. Development of organizational effectiveness evaluation system for tertiary education institutions under the Ministry of Education offers a good practice for proper evaluation of organizational effectiveness through strategic map (OECD, 2012).

The progression from monitoring to the management of quality in education requires the adoption of a system which is aimed not only at performance measurement (Bormans et al, 1998), but also taking into consideration the needs of all the stakeholders and focusing on the strategy towards the objectives of the various stakeholders (Kaplan and Norton, 2001). In order to be successful, the scorecard also needs to be rooted in the employees' internal commitment (Norreklit, 2000) and this requires the involvement of staff (Lazenby, 2009) in the development of performance management decisions. In the current study, the need to balance all aspects of performance is crucial when one considers many interested parties in Botswana tertiary education programmes. For instance, pressures related to research performance may cause problems in respect of some of the staffing requirements normally associated with professional accreditation. Economic pressures may be at odds with the need to manage staff-student numbers to ensure a positive and supportive learning experience (Biggs, 2003).

Amoako, (2008), emphasized that to face the challenges and evolution of the new, knowledge-based economy, countries has developed strategies to develop their human capital. Relevant examples can be found in the education reforms conducted by the Republic of South Africa, Zimbabwe, Namibia, and England. The evolution of the global economy towards a knowledge base process has modified the capacity to engage staff into such an approach and to 
be able to respond to rapidly changing economic situations through the availability of relevant and competent staff (ETSSP, 2015; Bruns, Deon and Harry, 2011; Bauer and Henkel, 1997). Those countries have achieved a higher level of economic development than Botswana, but their experience represent useful models to analyse options and constraints in human capital development. This study can also provide useful references on how to conduct education reforms as whole, as well as specific information on feasible actions for Botswana with respect to the country current economic and social situation and ongoing education reforms.

The above mentioned four countries human capital development strategies confirms the core advantage of a sequential and complementary approach to both industrial and education reforms with a long-term perspective. Of course, specific constraints (financial, political, population size, growth, structure, etc.) did influence the past reform policies. What is important for Botswana is to be able to link the capacity to develop internationally competitive sectors with the appropriate human capital. However, while conducting the needed education and labour market reforms, benefit from the dynamic impact of the chosen competitive sectors serves as factors of development for these reforms. The current situation in Botswana does present opportunities for the development of key competitive sectors in order to provide available resources in enhancing effectiveness in tertiary education as suggested by the previous studies (ETSSP, 2015; Burnett and Desmond, 2010).

The plans which the Ministry of Education and tertiary education in Botswana have made are more focused in the development that will make the following: ensure high levels of quality education performance by strengthening quality, relevance, social outreach of education; ensure an efficient system of management, effective community participation, through decentralisation, medium-term finance planning, development of Learner Protection Policy and ensure equal education access for all (ETSSP, 2015, Fredriksen and Jee, 2011). However, Botswana Qualification Authority must set teaching and learning standards for education and training providers; develop and review quality standards, evaluate resources and ensure compliance through monitoring and evaluation systems.

\section{Need for the Study}

Education and training have recently become among the highest priorities of the Botswana government, recognised as being key to Botswana desire to become more competitive and pivotal in its prospects for continued economic and social development. This can be realised by the Vision 2016 when the government was more concerned of creating an educated and informed nation through education and making all the local people to be able to have such (ETSSP, 2015; Bruns, Deon and Harry, 2011).

Serious reforms and modernisation initiatives are currently being implemented that should have a direct impact on the country's economic competitiveness. The most outstanding of these initiatives could be categorised under three main types: initiatives at policy level; initiatives to enhance quality and relevance of education and training; and initiatives to improve labour market efficiencies (ETSSP, 2015). In the recent years the government of Botswana has been creating the policies to develop the skills of the citizens through the Education Act No 17 of 2013 to create a Human Resources Development Council. This was done to improve the skills of the citizens and quality of the trainers in the country through assessing the qualifications which the personnel who are willing to be involved in education should be able to possess (ETSSP, 2015; Douglas and Douglas, 2006).

\section{Investment in the Education Sector}

There is need for increasing and diversifying funding for education which has also paid well for some countries in their pursuit to become more competitive. An example is Korea, were one of the main strengths of the Korean education system is the high investment in education (Fredriksen and Jee, 2011). Korea has a unique education system, characterized by much larger private sector representation and investment, and a relatively small publicly financed sector compared to other industrialized nations (Burnett and Desmond, 2010). Currently, the share of public financing in education is roughly $4.4 \%$ of GDP. In the past three decades, Korea has attained remarkable educational achievements. There is need for the developing countries like Botswana to invest many funds in the education sector so as to improve the skills of the people in the country and make the citizens to be equipped with many skills. In the past years Botswana government has been funding education in the tertiary sector and there is need to keep on sponsoring education (Brandley, 2008; ETSSP, 2015).

In order to measure the effectiveness of the strategies to improve education there is need to make strategies through international sources of education and training indicators, which have been used by many countries with diverse levels of development (Skelton, 2005). UNESCO's education indicators as defined in the technical guideline can be used as a relevant source to measure the situation and results of the education system as a whole. Each item is analysed on the basis of 10 evaluation factors: definition, purpose, calculation method, formula, data required, data 
source, types of disaggregation, interpretation, quality standards, and limitations (ETSSP, 2015; Shaughnessy and Zechmeister, 2012).

\subsection{Maintaining Quality Education through Bloom's Taxonomy}

In order to improve the skills of the leaner's in the Tertiary institutions in Botswana there is need for Ministry of Education to emphasize in the use of the Bloom taxonomy in order to increase the thinking capability of the learner's in the solving of the matter. Bloom taxonomy is a way of educational objectives used for developing higher level thinking skills (ETSSP, 2015). It is a process-oriented model that allows teachers to present ideas and concepts at many different levels to meet the needs of a variety of learners (Bloom, Canning and Chan, 2005). The method will be able to make the students to be able to understand the way in which they will get much of the information through comprehensions, application, analysis, synthesis and competitiveness (ETSSP, 2015).

In ensuring improvements in the quality of education, quality assurance framework should cover the key issue of certification and assessment that gives greater priority to the process of design, validation and certification of qualifications. The Human Resources Development Council in Botswana and Botswana Qualifications Authority should provide adequate information to ensure greater awareness of what 'accredited institution' means and for the education system to learn from ongoing experiences. The other improvement requires considering teachers as a key factor in the success of the ongoing reform, therefore there is a need to enhance professionalization of teaching staff and align incentives with better education outcomes, which should include evaluation of performance. Developing capacities, motivating and providing incentives of teaching staff is vital to improving education outcomes (ETSSP, 2015).

The accreditation process must be effective in improving real quality at Botswana Qualification Authority and that it will stimulate continuous improvement in the quality of teaching and learning (ETSSP, 2015; Cumming, Esnault, Konow and Skilbeck, 1997). Impact studies should be undertaken to provide evidence that accreditation processes have brought benefits at the institutional level. Secondly, the core accreditation requirements for Technical Vocational Education Tertiary schools and institutions should include interaction with labour market and employers' involvement in programming decisions and courses design. The mechanisms of the Tertiary Reform Programme's represent a permanent link between employers and educators should be encouraged and expanded in key sectors to ensure that market needs are constantly met by Tertiary institutions (ETSSP, 2015).

\subsection{Training and Development in Botswana}

The training and development of all the people should be the top national priority in the coming years. This will consider an increase in the expenditure on education and training through an allocation of a reasonable amount of the annual total public spending or of GDP to education and training respectively; full decentralisation of educational funds appropriations and utilisation; providing new educational tools of government finance, such as issuing treasury bills for financing education or public-private partnerships; allowing more financial and administrative independency for the schools and training centres and applying a national cost-sharing policy that allows different partners including the private sector to participate in covering part of the costs of their education and training, fully or partially, either through reasonable fees, aid, or soft loans; and adapting a new performance-based budgeting approach that bases the allocations to public higher-education institutions on their performance and student enrolment mix (ETSSP, 2015).

\section{Creation of Strong National Employment Strategy}

To improve efficiency of the Botswana labour market, there is a need to create a comprehensive country employment strategy that will focus much on the need identification. New programmes must be developed to meet identified market by surveys conducted, as appropriate, among learners, industry, and should also be in line with broad national requirements (Sangodoyin, 2016). This will be evidenced by but not restricted to the following; collation and analysis of prospective learner enquiries and National forums on labour/ skills requirements. Employment strategy would also eliminate the following challenges: narrow streaming in secondary education; early specialisation; lack of opportunities for multi-skill and second-chance learning; lack of career guidance services; lack of systematic surveying of graduate destinations; lack of routine surveys of employer satisfaction with graduates; and lack of a well designed national labour market information system (ETSSP, 2015). In addition to adequately addressing the challenge of low private returns to education as one of the main deep-rooted problems associated with education in Botswana, thus a revision of the structure of wages and salaries and the implementation of a comprehensive wage scheme that relates real wages to worker's productivity is also important. It entails initiating a national campaign through the media, drama and other outlets to improve the image and remove the stigma associated with education and related work (ETSSP, 
2015).

\section{Establishment of Research Institute in Botswana Education System}

Most institutions want to be recognised as providers of good quality higher education. They understand that competing on the basis of teaching is not only sufficient to ensure the reputation of the university (OECD, 2012). As such, they want to find new ways of demonstrating in valuable research: students want to ensure that their education will lead to jobs and will give them the skills needed in the society of today and tomorrow (Barrie and Prosser, 2002; Sangodoyin, 2016).

According to Brenda (2011) most institution-wide and quality assurance policies focuses on global projects designed to develop a quality culture at institutional level, like policy design, and support to organisation and internal quality assurance systems. Programme monitoring: including actions to measure the design, content and delivery of the programmes (through programme evaluation notably). Teaching and learning support: including initiatives targeting the teachers on the teaching side, the students on the learning side or both for example on the work environment. Examples include continuing education for faculty, pedagogy enhancement, student support for example mentoring and career advice, support for student learning focused on inputs, such as the introduction of new pedagogical tools, or on outputs, such as the development of certain abilities for the students (Sangodoyin, 2016). Tertiary commitments to quality teaching at top leadership level and at departmental level calls for leaders and staff to identify benchmarks, promotes good practices and scale them up across departments, and think up effective support that meets teacher and student expectations. An institutional policy reflects the will of the leaders and heads of departments to better understand the teaching process and the experiences initiated by teams or individual teachers. A quality teaching framework allows the institution to monitor support, track teacher and student satisfaction, and study the impact on the learning process.

\subsection{Botswana Qualification Authority (BQA)}

Botswana Qualification Authority is mandated to maintain a National Credit and Qualifications Framework that recognise the support of quality training and skills development. It makes the tertiary institutions that want to improve and be involved to remain an adventurous, lengthy and potentially rewarding project provider. Close monitoring of quality teaching support has been necessary to encourage broad endorsement within the academic community, avoiding the risk of attracting only the most motivated teachers. A flexible institutional framework, and higher level of teacher autonomy and a collaborative would be needed (ETSSP, 2015; QAA, 2006).

\subsection{Quality Management Leads to Quality Teaching}

The development of formal quality assurance systems is one of the most significant trends in tertiary education systems during the past few decades (Hamish, 2005; Douglas and Douglas, 2006; OECD, 2012). According to Brenda (2011) in the early 1980s, quality became a key topic in tertiary education policy: the expansion of tertiary education raised questions about the level and direction of public expenditure. Botswana Quality Assurance Management clearly states that the objectives and mechanisms of the quality management are integrated into institutional planning. It emphasised that there is provision for involvement of learners, staff and external partners in the quality management system implementation, monitoring and evaluation. The effects of quality assurance evaluations audits, programme accreditation or institutional evaluations remain controversial. Nevertheless, there is no doubt that national quality assurance systems foster institutional involvement in supporting quality teaching. External reviews carried out by dedicated bodies quality assurance, accreditation or evaluation agencies encourage institutions to set up or reinforce internal quality assurance mechanisms by including a quality teaching aspect. In most cases recommendations require mandatory corrective actions (Rashida, Gabdrakhmanova, Guzel, Kalimullira, Viya and Ignatovich, 2016).

\subsection{Linkages of the Programmes and Curricular}

Most tertiary institutions in Botswana need to be called upon to ensure the coherence of their programmes and curricula within each programme, and the quality of the learning environment, availability of equipment, mentoring students. Recommendations will influence organisational structures, and improve quality teaching at the level of the whole institution. In expanding the tertiary institutions in Botswana, there is need for diversification of providers. New institution types should be allowed to emerge, educational offerings within institutions multiplied, private provision expanded, and new modes of delivery are introduced (OECD, 2012). 


\subsection{Improving the Quality of Teaching Methods in Tertiary Institutions}

Higher education has become much more diversified, encompassing new types of institutions such as technical colleges and university colleges. These have been created for a number of reasons to develop a closer relationship between tertiary education and the external world, including greater responsiveness to labour market needs; to enhance social and geographical access to tertiary education; to provide high-level occupational preparation in a more applied and less theoretical way; and to accommodate the growing diversity of qualifications and expectations of school graduates (OECD, 2008).

Higher education institutions need to provide wider range of teaching than their traditional degree-level courses for example now the colleges in Botswana are offering Vocational courses to cater for other different courses. Some higher education institutions need to offer adult education and leisure courses, upper secondary courses to prepare students for tertiary-level study, and short specific occupational preparation at sub-degree level (OECD, 2008). The nature of some programmes is likely to lead institutions to further consider quality teaching, especially medium-sized institutions with a limited range of degrees colleges or universities of applied sciences that grant Bachelor degrees. Three major reasons together lead vocational-type institutions to closely investigate the notion of quality teaching. The teaching process is driven by academics, mostly practitioners from the corporate world who are experts in their field but not necessarily is sometimes denounced. The diversity of employment statutes within the institution professionals, international teachers, part-time teachers, etc, will make the organisation to improve and have different skills to share knowledge combined with an increasing variety of students might result in incoherence and inequity of the teaching process. Applied research traditionally nourishes curricula and the link between updated knowledge and teaching is crucial (Fredriksen and Jee, 2011).

\subsection{Increasing Student Demand for Quality Teaching}

In order to improve quality there is need for students to increasingly becoming a driver for quality teaching. In countries where students have a recognised status, they play an active role and are a powerful respected body. According to Duncan (2012) current international trend likely to increase awareness of quality teaching is that students are invited to serve on governing bodies or hired as evaluation experts on par with academic peer reviewers. At the Dublin Institute of Technology, students serve on the board of audits and raise concerns about teaching, learning environments, quality of content and teacher attitude (Ellet et al, 1997).

In career-oriented or vocational training programmes, students may complain of lack of programme consistency or poor practice-based learning, even when they are mature or working students. Student and alumni associations can easily benchmark learning conditions, teacher attitudes, pedagogy and support, and hence may promote or undermine the reputation of the institutions (ETSSP, 2015).

\section{Conclusions}

Commitment on the part of all tertiary stakeholders, and above all by the academic community, is crucial to the success of any policy to improve the quality of teaching. Participation bolsters the dedication and motivation of supervisors when it begins at the very conception of an action or a policy in which their educational function is put forward and stated explicitly. The participation of faculty heads is also vital in so far as deans, at the crossroads between an institutions-making bodies and teacher's decision about the job, encourage the cross-fertilisation of strategic approaches, build and support communities of practice, and nurture innovation in everyday practice in the classroom. The deployment of policies for the quality strikes a balance between technical aspects of quality support for example development of course evaluation questionnaires and the fundamental issues rose assessing the added value of the teaching initiatives in achieving curriculum objectives. Clearly, goals related to the quality of teaching can be neither reduced to, nor achieved through more technical improvements or extensions of existing mechanisms. The fundamental issues lose relevance if they are not backed up by specific actions deemed useful by the academic community. It is all a matter of balance, tailored specifically to the culture and modus operandi of each institution.

Quality teaching initiatives have emphasised the role of teaching in the educational transformative process, have refined the interaction between research and teaching, and have nurtured the culture of quality within the academic community. However, institutions need to develop innovative evaluative approaches to measure the impact of their support on quality teaching. The tertiary education sector is still struggling to understand the causal link between engagement in teaching and the quality of learning outcomes. The reason for this lies in the difference in approach of learning between activities, which makes teachers a causal link between inputs and outcomes difficult to measure, although such links undoubtedly exist. 


\section{References}

Amoako, K.Y. (2008). Meeting global challenges: International Cooperation in the National Interest. In Kasekende, L. and M. Kisubi (Eds.), Eminent Speakers Series: Sharing Visions of Africa's Development (Vol. 1). African Development Institute, Tunis.

Barrie, S.C., \& Prosser, M. (2002). Aligning research on student learning with institutional policies and practices on evaluation and quality assurance. Paper presented at the 11th ISL Conference, Brussels, 4-6.

Bauer, M., \& Henkel, M. (1997). Responses of Academe to Quality Reforms in Higher Education: A Comparative Study of England and Sweden. Tertiary Education and Management, 3(3), 211-228. https://doi.org/10.1080/13583883.1997.9966924

Biggs, J. (2003). The reflective institution: assuring and enhancing the quality of teaching and learning. Higher Education, 41(3), 221-238. https://doi.org/10.1023/A:1004181331049

Bloom, D, Canning, D., \& Chan, K. (2005). Higher Education and Economic Development in Africa. Harvard University.

Bormans, M.J., Brouwer, R., Veld, R.J., \& Mertens, F.J. (1998). The role of performance indicators in improving the dialogue between government and universities. International Journal of Institutional Management in Higher Education, 11(2), 181-194.

Bradley. (2008). Review of Australian Higher Education Final Report (the Bradley Review). Australian Government.

Bruns, B., Deon, F., \& Harry, P. (2011). Making Schools Work: New Evidence on Accountability Reforms. World Bank, Washington DC. https://doi.org/10.1596/978-0-8213-8679-8

Burnett, N., \& Desmond, B. (2010). Innovative Financing for education. ESP Working Papers Series, 2010 No 5. Results for Development Institute and Open Society Institute.

Cummings, W., Esnault, E., Konow, G., \& Skilbeck, M. (1997). Thematic Review of the First Years of Tertiary Education Report. (Redefining Tertiary Education.)PEB Exchange, OECD, Japan.

Douglas, J., \& Douglas, A. (2006). Evaluating Teaching Quality. Quality in Higher Education, 12(1). https://doi.org/10.1080/13538320600685024

Ellet, C., Loup, K., Culross, R.J., McMullen, \& Rugutt, J. (2007). Assessing Enhancement of Learning, Personal learning Environment, and Student Efficacy: Alternatives to Traditional Faculty Evaluation in Higher Education. Journal of Personnel Evaluation in Education, 11(5).

ETSSP. (2015). Education and training sector strategic plan in Botswana (2015-2020).

Fredriksen, B., \& Jee, P.T. (2011). An African Exploration of East Asian Education Experience. World Bank, Washington, DC.

Lazenby, K. (2009). Strategic Management (2nd ed.). Pretoria: VanSchairk Publishers.

Mbuya, T. (2017). The decline and fall of higher education in Botswana: Quality assurance authorities complicit. Mmegi. Retrived January 20, 2017, from www.mmegi.bw

OECD. (2008). On the edge: Securing a sustainable future for higher education. Report of the OECD/IMHE-HEFCE Project on Financial Management and Governance of Higher Education Institutions. Paris, pp. 44.

OECD. (2012). Tertiary Education for the Knowledge Society, Vol. 1, OECD, Paris.

QAA. (2006). Outcomes from institutional audit programme monitoring arrangements. The Quality Assurance Agency for Higher Education, United Kingdom.

Sangodoyin, O. O. (2016). The evaluation of education resources to enhance effectiveness, and high quality of training in the tertiary sector in Botswana. Thematic Independent Study, University of Greenwich. UK.

Shaughnessy, J., \& Zechmeister, B. (2012). Research Methods in Psychology. Tata McGraw Hill Illinois.

Skelton, A. (2005). Understanding Teaching Excellence in Higher Education: Towards a critical approach. Routledge, Oxon. https://doi.org/10.4324/9780203412947

Vision 2036. Achieving Prosperity for All. Retrieved from www.vision2036.co.bw 